\title{
Assessment of exposure to DDT and metabolites after indoor residual spraying through the analysis of thatch material from rural African dwellings
}

\author{
Maria N. Manaca $\cdot$ Joan O. Grimalt $\cdot$ Merce Gari • \\ Jahit Sacarlal • Jordi Sunyer • Raquel Gonzalez • \\ Carlota Dobaño $\cdot$ Clara Menendez $\cdot$ Pedro L. Alonso
}

Received: 21 March 2011 / Accepted: 29 August 2011 /Published online: 18 September 2011

(C) The Author(s) 2011. This article is published with open access at Springerlink.com

\begin{abstract}
Introduction We report on the analysis of 4,4'-dichlorodiphenyltrichloroethane $\left(4,4^{\prime}\right.$-DDT) and its metabolites in thatch and branch samples constituting the wall materials of dwellings from South African subtropical areas. This approach was used to assess the exposure to DDT in the residents of the dwellings after indoor residual spraying (IRS) following recommended sanitation practices against malaria vectors.
\end{abstract}

Responsible editor: Ake Bergman

M. N. Manaca $\cdot$ J. Sacarlal $\cdot$ R. Gonzalez $\cdot$ C. Dobaño $\cdot$

C. Menendez $\cdot$ P. L. Alonso

Centro de Investigaçao em Saúde da Manhiça (CISM),

Maputo, Mozambique

M. N. Manaca $\cdot$ J. O. Grimalt $(\bowtie) \cdot$ M. Gari

Institute of Environmental Assessment and Water Research

(IDÆA-CSIC),

Jordi Girona, 18,

08034 Barcelona, Catalonia, Spain

e-mail: joan.grimalt@idaea.csic.es

M. N. Manaca $\cdot$ R. Gonzalez $\cdot$ C. Dobaño $\cdot$ C. Menendez

P. L. Alonso

Barcelona Centre for International Health Research (CRESIB),

Hospital Clínic, Universitat de Barcelona,

Rosselló 132, 4a,

08036 Barcelona, Catalonia, Spain

J. Sunyer

Centre for Research in Environmental Epidemiology (CREAL),

Doctor Aiguader, 88,

08003 Barcelona, Catalonia, Spain

J. Sunyer • R. Gonzalez • C. Dobaño · C. Menendez • P. L. Alonso Ciber Epidemiología y Salud Pública,

Barcelona, Spain
Discussion Examination of the distributions of DDT compounds (2,4'-DDT, 4,4'-DDT and its metabolites) in 43 dwellings from the area of Manhiça (Mozambique) has shown median concentrations of 19,130 , and $23 \mathrm{ng} / \mathrm{g}$ for 2,4'-DDT, 4,4'-DDT, and 4,4'-DDE, respectively, in 2007 when IRS implementation was extensive. The concentrations of these compounds at the onset of the IRS campaign $(n=48)$ were $5.5,47$, and $2.2 \mathrm{ng} / \mathrm{g}$, respectively. The differences were statistically significant and showed an increase in the concentration of this insecticide and its metabolites. Calculation of 4,4'-DDT in the indoor air resulting from the observed concentrations in the wall materials led to the characteristic values of environments polluted with this insecticide.

Keywords DDT Thatch $\cdot$ Typha $\cdot$ Indoor residual spraying $\cdot$ Air concentrations $\cdot$ Malaria

\section{Introduction}

Indoor residual spraying (IRS) is one of the primary interventions for vector control in the efforts for reducing malaria transmission. Accordingly, long-acting chemical insecticides are sprayed on the walls and roofs of all structures in a determined area to kill the mosquitoes that land and rest there (Montgomery et al. 2010). Dichlorodiphenyltrichloroethane (DDT) is one of the most effective insecticides due to its persistence and relatively low cost; it either kills mosquitoes resting on the walls or repels them from dwelling. IRS with DDT is still recommended by WHO $(2006,2007)$, and at present, it is an important source and direct input of the insecticide residues in African domestic environments (van Dyk et al. 2010; Sereda et al. 
2009). Because of its toxicity, DDT use is at present restricted to public health purposes (UNEP 2008).

Residents are exposed to DDT through their daily activities in and around the house (Van Dyk et al. 2010). Various studies have shown high DDT levels in the environment and populations of areas where DDT has been applied in IRS programs for malaria control (Van Dyk et al. 2010; Röllin et al. 2009; Barnhoorn et al. 2009; Yáñez et al. 2002). They included measurements of the concentrations of this compound in indoor air, floor dust, outdoor soil, birds, sediment, food, and water (Van Dyk et al. 2010; Barnhoorn et al. 2009; Singh et al. 1992). However, the insecticide residues remaining in the thatch and branches (usually stems of Typha plants, particularly Typha latifolia) of the wall materials of many dwellings (many of them also covered by daub) remain to be quantified in rural areas of malaria endemic African countries. In Mozambique, these materials are sprayed directly during IRS and constitute the DDT standing stock after application. Partial volatilization of the insecticide accumulated in the walls likely determines the DDT indoor air concentrations and therefore contribute to the exposure of inhabitants

At the end of 2005, house spraying with DDT in Mozambique was reintroduced in public health programs. This compound has now become the main insecticide for malaria vector control because no resistance to DDT has been detected in Mozambican mosquitoes (Casimiro et al. 2006; 2007). In the Manhiça district, in particular, DDT was reintroduced for IRS in 2006.

The present study describes the analysis of DDT levels in wall materials with the purpose of assessing the exposure of dwelling residents to the insecticide after implementation of IRS as a public health tool for malaria vector control. The study was carried out in dwellings from the Manhiça district, a rural area of southern Mozambique. This subtropical area provides a representative example of the current exposure levels associated with IRS in people living in thatch-walled huts.

\section{Materials and methods}

\subsection{Study area}

The Manhiça district is located in the north of the Maputo province, $80 \mathrm{~km}$ from the capital city (Maputo), and has 159,000 inhabitants. There are two distinct seasons: one warm and rainy between November and April and another dry and cooler for the rest of the year. Most of the inhabitants are farmers who grow sugar cane, banana, and rice and some work in two nearby big sugar cane factories. The typical houses in the Manhiça area are cylindrical, with diameters and height of about 6 and $2 \mathrm{~m}$, respectively. They are mostly made of reeds with roofs of corrugated zinc or thatch. The thatches from the roofs of the houses are usually replaced every 4 years. These dwellings are similar to others studied in Vhembe District (Limpopo Province, South Africa; van Dyk et al. 2010) that are also built in a compact circular arrangement (diameter 3-5 m). Their roofs are also made of thatch and the walls consist of a mixture of mud and cement.

The DDT used for IRS is a 75\% wettable powder (CAS register number 59-29-3). One sachet of $670 \mathrm{~g}$ of DDT is mixed into a portable sprayer with $10 \mathrm{~L}$ of water and shaken before spraying. This is done by the IRS spray teams from the Mozambique Ministry of Health (MISAU).

Typical dwellings in Manhiça involve a total wall and roof surface area of about 38 and $28 \mathrm{~m}^{2}$, respectively. In the current IRS practice, about $3 \mathrm{~g} / \mathrm{m}^{2}$ of DDT is sprayed, which involves about $200 \mathrm{~g}$ per regular dwelling.

\subsection{Sample collection}

The dwelling thatch samples included in the study were collected in May $2006(n=48)$ and February-March 2007 $(n=43)$ and were taken from the same dwellings. In September 2006, the Mozambique Ministry of Health (MISAU) through the National Malaria Control Program expanded the IRS with DDT into the Manhiça district through the National Malaria Control Program. The samples were collected, placed in sterile and resistant polyester bags (Kapak Corporation, Minneapolis, MN, USA), sealed using a heat sealer, and stored at $-20^{\circ} \mathrm{C}$ until extraction.

Ethics approval for the study was obtained from the National Mozambican Ethics Review Committee. Informed consent was obtained from all owners of the dwellings prior to thatch collection.

\subsection{Chemicals analysis}

Standards of tetrabromobenzene (TBB); polychlorobiphenyls (PCB) 142, 200, 209; and DDTs were purchased from Dr. Ehrenstorfer (Augsburg, Germany). All standard solutions were prepared in isooctane for organic trace analysis (Merck, Darmstadt, Germany). Analytical grade concentrated sulfuric acid, dichloromethane (DCM), methanol, cyclohexane, and $n$-hexane were also from Merck.

\subsection{Extraction procedures}

Samples were thawed at room temperature before extraction. Then, they were minced by stainless steel scissors and homogenized with liquid nitrogen in mortars. About $0.5-$ $2.5 \mathrm{~g}$ of the homogenized material was put in $25 \mathrm{~mL}$ tubes and extracted with DCM/hexane (1:4). TBB, PCB 209, and 
PCB 200 were added as surrogate standards, and the mixture was vortexed stirred for $1 \mathrm{~min}$ at 2,000 rpm for homogenization. Extraction was performed after addition of $20 \mathrm{~mL}$ of solvent mixture and sonication for $20 \mathrm{~min}$ and subsequent centrifugation for $5 \mathrm{~min}$ at 2,000 rpm. This last step was repeated three times. The combined extract of $60 \mathrm{~mL}$ of solvent was reduced to $1 \mathrm{~mL}$ by vacuum rotary evaporation operated at $30^{\circ} \mathrm{C}$. The solution was transferred into a $10-\mathrm{mL}$ centrifuge tube using several rinses of $n$-hexane (approximately $3 \mathrm{~mL}$ ), and $2 \mathrm{~mL}$ of concentrated sulfuric acid was added. After reaction, the mixture was stirred for $30 \mathrm{~s}$, centrifuged for $10 \mathrm{~min}$, and the remaining sulfuric acid solution was discarded. Subsequent cleanup with concentrated sulfuric acid was done. The supernatant $n$-hexane phase was transferred to a conical tube and reduced to nearly dryness under a gentle nitrogen flow. The extract was transferred to gas chromatography (GC) vials with four $25 \mu \mathrm{L}$ rinses of isooctane. Before injection, it was re-evaporated under nitrogen, and $100 \mu \mathrm{L}$ of a PCB142 standard was added as injection standard (Grimalt et al. 2010).

\section{$2.5 \mathrm{GC}$ analysis}

The concentrations of 2,4'-DDT, 4,4'-DDT, 2,4'-DDE, 4,4'DDE, 2,4'-DDD, and 4,4'-DDD were determined by GC with electron capture detection (Hewlett Packard $6890 \mathrm{~N}$ GC-ECD). Samples were injected $(2 \mu \mathrm{L})$ in splitless mode onto a 60-m DB-5 column protected with a retention gap (J\&W Scientific, Folsom, CA, USA). The temperature program started at $90^{\circ} \mathrm{C}$ (held for $2 \mathrm{~min}$ ) and increased to $140^{\circ} \mathrm{C}$ at $20^{\circ} \mathrm{C} / \mathrm{min}$, then to $200^{\circ} \mathrm{C}$ (held for $13 \mathrm{~min}$ ) at $4^{\circ} \mathrm{C} /$ $\mathrm{min}$, and finally to $310^{\circ} \mathrm{C}$ (held for $10 \mathrm{~min}$ ) at $4^{\circ} \mathrm{C} / \mathrm{min}$. Injector, ion source, and transfer line temperatures were $250^{\circ} \mathrm{C}, 176^{\circ} \mathrm{C}$, and $280^{\circ} \mathrm{C}$, respectively.

The quantification procedure is described in detail elsewhere (Garí and Grimalt 2010). The identification of organochlorine compounds was based on retention time. Selected samples were analyzed by GC coupled to mass spectrometry for structural confirmation. Calibration straight lines were obtained for all analytes. These standard solutions also contained the injection standards. Quantification was performed by the external standard method using these calibration lines and recovery (TBB and PCB-209) and injection (PCB-142) standards. The use of PCB-142 to correct for volume allows differentiating between corrections due to analyte losses by sample handling and volume variations in the final solvent rinsings for sample introduction into the chromatographic vials. Thus, the recovery standards are also corrected by the injection standard. Limits of detection (LOD) and quantification (LOQ) were calculated from blanks. One blank was included in each sample batch. $\mathrm{LOD}=$ mean of all blanks +3 times the standard deviations. $\mathrm{LOQ}=$ mean + 10 times the standard deviation. When the compound was absent from the blanks, LOD and LOQ were determined from instrumental limits of detection using injection of dilutions of standards.

Concentrations below LOQ were substituted by half of the LOD. Univariate statistics were calculated as customary (Rothman et al. 2008). This method performed satisfactorily in repeated international intercalibration exercises within the Arctic Monitoring and Assessment Programme (AMAP 2008). Total DDTs ( $\left.\sum D D T\right)$ were calculated by the sum of the concentrations of $4,4^{\prime}$-DDT, 2,4'-DDT, $4,4^{\prime}$ DDE, 2, $4^{\prime}$-DDE, 4,4'-DDD, and 2,4'-DDD. The DDT/DDE ratio was calculated by the division of $4,4^{\prime}-\mathrm{DDE}$ by $4,4^{\prime}-$ DDT. In order to obtain a normal distribution, data were log-transformed for application of $t$ tests to compare mean concentrations of the same dwellings sampled in 2006 and 2007. All statistical analyses were performed using the Statistical Package for the Social Science (SPSS for Windows version 15), and the figure was produced with GraphPad Prism5. The statistical significance was set at $p<0.05$ (two sided).

\section{Results}

The variation of the concentrations in the wall materials after IRS could be assessed by replicate sampling of wall materials from different sites in the same dwelling and independent analysis of each collected material $(n=3$ or 4 ; Table 1); this subsampling was done in 2008. The observed standard deviation of 4,4'-DDT concentrations from the same dwelling ranges between $17 \%$ and $65 \%$ of the mean values. Similar percent values were observed for the standard deviations of 4,4'-DDE and 4,4'-DDD except when the concentrations of some metabolite were found below the limit of detection which involved higher standard deviation values. Within these ranges, the degree of variation between samples from the same dwelling did not seem to be influenced by the absolute concentrations. Table 2 shows the levels of DDTs (nanograms per gram) in thatch samples from this study in Mozambique compared to DDT levels found in similar (but not equivalent) materials in studies conducted in other countries.

Thatch collected in 48 and 43 dwellings in 2006 and 2007, respectively, were analyzed. In 2007, we could not repeat sampling in five dwellings sampled in 2006, and two other dwellings were not sprayed in 2007. In order to perform a close $t$ test mean comparison, we excluded from the calculation of the mean values of 2006 the dwellings that were not sprayed or sampled in 2007. Therefore, the results in Table 3 are just based on 41 thatch pairs. 4,4'DDT, 2,4'-DDT, 4,4'-DDE, and 4,4'-DDD were quantifiable 
Table 1 Concentrations (nanograms per gram dry mass) of DDT and metabolites in repeated thatch sampling $(n=3$ or 4$)$ from the same dwelling in 2008

$\mathrm{LOD}=0.01 \mathrm{ng} / \mathrm{g}$

\begin{tabular}{|c|c|c|c|c|c|}
\hline Dwelling & Sample & $4,4^{\prime}-\mathrm{DDE}$ & $4,4^{\prime}-\mathrm{DDD}$ & $2,4^{\prime}$-DDT & $4,4^{\prime}$-DDT \\
\hline \multirow[t]{7}{*}{ A } & 1 & 180 & 34 & 260 & 2,100 \\
\hline & 2 & 56 & 54 & 190 & 950 \\
\hline & 3 & 90 & 28 & 680 & 1,800 \\
\hline & 4 & 72 & 29 & 87 & 330 \\
\hline & Mean & 99 & 36 & 310 & 1,300 \\
\hline & SD & 54 & 12 & 260 & 810 \\
\hline & $\% \mathrm{SD} /$ mean & 55 & 33 & 85 & 62 \\
\hline \multirow[t]{7}{*}{ B } & 1 & 98 & 22 & 47 & 160 \\
\hline & 2 & 82 & 43 & 69 & 290 \\
\hline & 3 & 46 & 13 & 25 & 99 \\
\hline & 4 & 33 & 11 & 14 & 63 \\
\hline & Mean & 65 & 22 & 39 & 150 \\
\hline & SD & 30 & 15 & 24 & 100 \\
\hline & $\% \mathrm{SD} /$ mean & 47 & 65 & 63 & 65 \\
\hline \multirow[t]{6}{*}{$\mathrm{C}$} & 1 & 11 & 10 & 86 & 210 \\
\hline & 2 & $<\mathrm{LOD}$ & 7.4 & 23 & 85 \\
\hline & 3 & 19 & 11 & 150 & 350 \\
\hline & Mean & 10 & 9.6 & 86 & 210 \\
\hline & SD & 9.5 & 2.0 & 63 & 130 \\
\hline & $\% \mathrm{SD} /$ mean & 94 & 20 & 73 & 62 \\
\hline \multirow[t]{7}{*}{ D } & 1 & 8.4 & 6.7 & 40 & 220 \\
\hline & 2 & $<\mathrm{LOD}$ & 6.2 & 30 & 170 \\
\hline & 3 & 15 & 4.8 & 32 & 140 \\
\hline & 4 & $<\mathrm{LOD}$ & 8.6 & 38 & 220 \\
\hline & Mean & 5.9 & 6.6 & 35 & 190 \\
\hline & SD & 7.1 & 1.6 & 5.1 & 38 \\
\hline & $\% \mathrm{SD} /$ mean & 120 & 23 & 14 & 20 \\
\hline
\end{tabular}

in $94 \%, 92 \%, 98 \%$, and $98 \%$ of the samples of the first group, respectively. In the 2007 group, 4,4'-DDT, 2,4'DDT, 4, $4^{\prime}$-DDE, and 4,4'-DDD were found at quantitative levels in $98 \%, 95 \%, 93 \%$, and $93 \%$ of the samples, respectively. Total DDT concentrations ranged between 0.6 and $6100 \mathrm{ng} / \mathrm{g}$ in the materials collected in 2006. The predominant isomer was $4,4^{\prime}-\mathrm{DDT}$ (median $=49 \mathrm{ng} / \mathrm{g}$ ) followed by $4,4^{\prime}$-DDD (median=5.2 ng/g) and 4,4'-DDE (median=2.2 ng/g). The 2,4'-isomers for DDE, DDD, and
DDT $(0.2,1.0$, and $7.5 \mathrm{ng} / \mathrm{g}$, respectively) were in lower concentration than the $4,4^{\prime}$-isomers except in two samples from the 2006 series.

The materials sampled in 2007 were from sprayed dwellings; the concentrations of total DDT ranged between 12 and 29,000 ng/g (Table 3). The predominant isomer was 4,4'-DDT (median=150 ng/g) followed by 4,4'-DDD (median=23 ng/g) and 4,4'-DDE (median=21 ng/g). The concentration of the $2,4^{\prime}$-isomers for DDE, DDD, and DDT

Table 2 Comparison of DDTs concentrations (mean, nanograms per gram) in materials sampled after IRS with DDT for malaria control in various countries (nanograms per gram)

\begin{tabular}{llllccrrr}
\hline Country & Survey year & $n$ & Sample type & $4,4^{\prime}$-DDE & $4,4^{\prime}$-DDD & 4,4'-DDT & EDDT & Reference \\
\hline Mozambique & 2006 & 48 & Straw & 2.2 & 5.5 & 47 & 56 & Present study \\
Mozambique & 2007 & 43 & Straw & 20 & 23 & 130 & 180 & Present study \\
India & 1986 & 20 & Wheat straw & 30 & - & 260 & 460 & Singh and Chawla 1988 \\
Mexico $^{2003}$ & 50 & Rye straw & 8 & - & 44 & - & Waliszewski et al. 2004 \\
Tanzania $^{\text {a }}$ & 2002 & 6 & Dried hay & 72 & 641 & 6,900 & 79,000 & Marco and Kishimba 2005 \\
\hline
\end{tabular}

${ }^{\mathrm{a}}$ Mean 
Table 3 Concentrations of DDTs (nanograms per gram wet weight) and metabolites in thatch sampled in 2006 and 2007

\begin{tabular}{|c|c|c|c|c|c|c|c|c|}
\hline & $\begin{array}{l}\text { 4,4'-DDE } \\
(\mathrm{ng} / \mathrm{g})\end{array}$ & $\begin{array}{l}\text { 4,4'-DDD } \\
\text { (ng/g) }\end{array}$ & $\begin{array}{l}\text { 4,4'-DDT } \\
\text { (ng/g) }\end{array}$ & $\begin{array}{l}2,4^{\prime}-\mathrm{DDE} \\
(\mathrm{ng} / \mathrm{g})\end{array}$ & $\begin{array}{l}\text { 2,4'-DDD } \\
\text { (ng/g) }\end{array}$ & $\begin{array}{l}\text { 2,4'-DDT } \\
\text { (ng/g) }\end{array}$ & $\begin{array}{l}\sum \mathrm{DDT} \\
\text { (ng/g) }\end{array}$ & $\begin{array}{l}\mathrm{DDE} / \mathrm{DDT} \\
(\mathrm{ng} / \mathrm{g})\end{array}$ \\
\hline \multicolumn{9}{|l|}{$2006(n=41)$} \\
\hline Mean & 9.4 & 35 & 270 & 0.7 & 4.8 & 28 & 350 & 0.3 \\
\hline Median & 2.2 & 5.2 & 49 & 0.2 & 1.0 & 7.5 & 70 & 0.0 \\
\hline $\mathrm{SD}$ & 23 & 83 & 790 & 1.4 & 9.9 & 63 & 960 & 1.1 \\
\hline Min & 0.0 & 0.1 & 0.05 & 0.03 & 0.1 & 0.1 & 0.6 & 0.01 \\
\hline $\operatorname{Max}$ & 140 & 480 & 5,000 & 8.7 & 55 & 390 & 6,100 & 5.7 \\
\hline $25 \%$ percentile & 1.0 & 1.9 & 12 & 0.03 & 0.4 & 2.2 & 21 & 0.04 \\
\hline $75 \%$ percentile & 10 & 23 & 210 & 0.5 & 3.5 & 26 & 270 & 0.1 \\
\hline \multicolumn{9}{|l|}{$2007(n=41)$} \\
\hline Mean & 190 & 470 & 1,300 & 7.5 & 110 & 240 & 2,400 & 0.1 \\
\hline Median & 21 & 23 & 150 & 0.3 & 5.4 & 21 & 220 & 0.1 \\
\hline $\mathrm{SD}$ & 470 & 1,400 & 3,700 & 22 & 360 & 650 & 6,400 & 0.1 \\
\hline Min & 0.2 & 0.1 & 0.5 & 0.3 & 0.1 & 0.01 & 1.2 & 0.001 \\
\hline Max & 1,900 & 7,700 & 20,000 & 95 & 2,100 & 3,200 & 29,000 & 0.6 \\
\hline $25 \%$ percentile & 0.2 & 6.3 & 45 & 0.3 & 0.1 & 11 & 74 & 0.003 \\
\hline $75 \%$ percentile & 73 & 200 & 850 & 0.3 & 39 & 140 & 1,200 & 0.2 \\
\hline Wilcoxon test $\mathrm{t}^{\mathrm{a}}$ & 0.002 & 0.002 & 0.002 & 0.001 & 0.008 & 0.002 & 0.000 & \\
\hline
\end{tabular}

${ }^{\text {a }}$ Calculated over log-transformed data for normalization

$(0.3,5.4$, and $21 \mathrm{ng} / \mathrm{g}$, respectively) were lower than those among the 4,4'-isomers. Both in 2006 and 2007, the concentrations exhibited large standard deviations as consequence of the high values in some dwellings. The 2007 dataset exhibited higher maximum concentrations than that of 2006. These high values were consistent with the spraying in September 2006 of the studied dwelling. They showed a strong dispersion in DDT concentration among the different dwellings after IRS.

The concentrations of all DDT isomers and their metabolites were higher in thatch samples collected in year 2007 than in 2006. Comparison of the means of the logtransformed data of these two sample populations shows that their differences were statistically significant in all cases $p<0.05$ (Fig. 1). The comparison is useful to support that average concentrations were statistically significantly higher after IRS despite referring to two independent episodes. As mentioned above, the two means referred exactly to the same dwellings before and after IRS.

\section{Discussion}

In this study, we found that the concentrations of 4,4'-DDT were higher (ten times or more) than those of the other isomers in all samples, except two from the 2006 series. This finding is consistent with recent use of the commercial insecticide. Conversion of 4,4'-DDT into $4,4^{\prime}$-DDE starts after application but the half-life of the former could be years. Accordingly, the historical environmental DDT record is dominated by $4,4^{\prime}$-DDE because this is the most chemically stable metabolite of the insecticide. In Manhiça, dominance of 4,4'-DDT was observed even in samples with low total DDT levels indicating that the whole area has been under the influence of emissions from this insecticide, maybe as consequence of misuses and poor management (MISAU 2006).

Total DDT levels in thatch in 2007 were significantly higher than in 2006 (Table 2). The strong difference may reflect the more widespread application of IRS in 2007 compared to 2006. The 4,4'-DDT levels measured in 2007 were considerably higher than those found in other types of applications such as thatch treated with DDT in Mexico (Waliszewski et al. 2004). However, they were lower than those found in Tanzania in dried hay samples collected in the vicinity of an old storage site, which represented a point source of contamination (Marco and Kishimba 2005). It has been reported that DDT levels increase in commodities stored in rural houses treated with DDT for malaria control (Battu et al. 1989; Singh et al. 1991). The total 4,4'-DDT medians in the Manhiça thatch samples were similar to those found in Indian wheat straw samples stored in dwellings treated with IRS (Battu et al. 1989).

The standard deviation of the 4,4'-DDT distribution in the dwellings as consequence of IRS was in the order of $20-65 \%$ of the mean concentration values (Table 1). 4,4'DDD and 2,4'-DDT exhibited similar values and 4,4'-DDE 

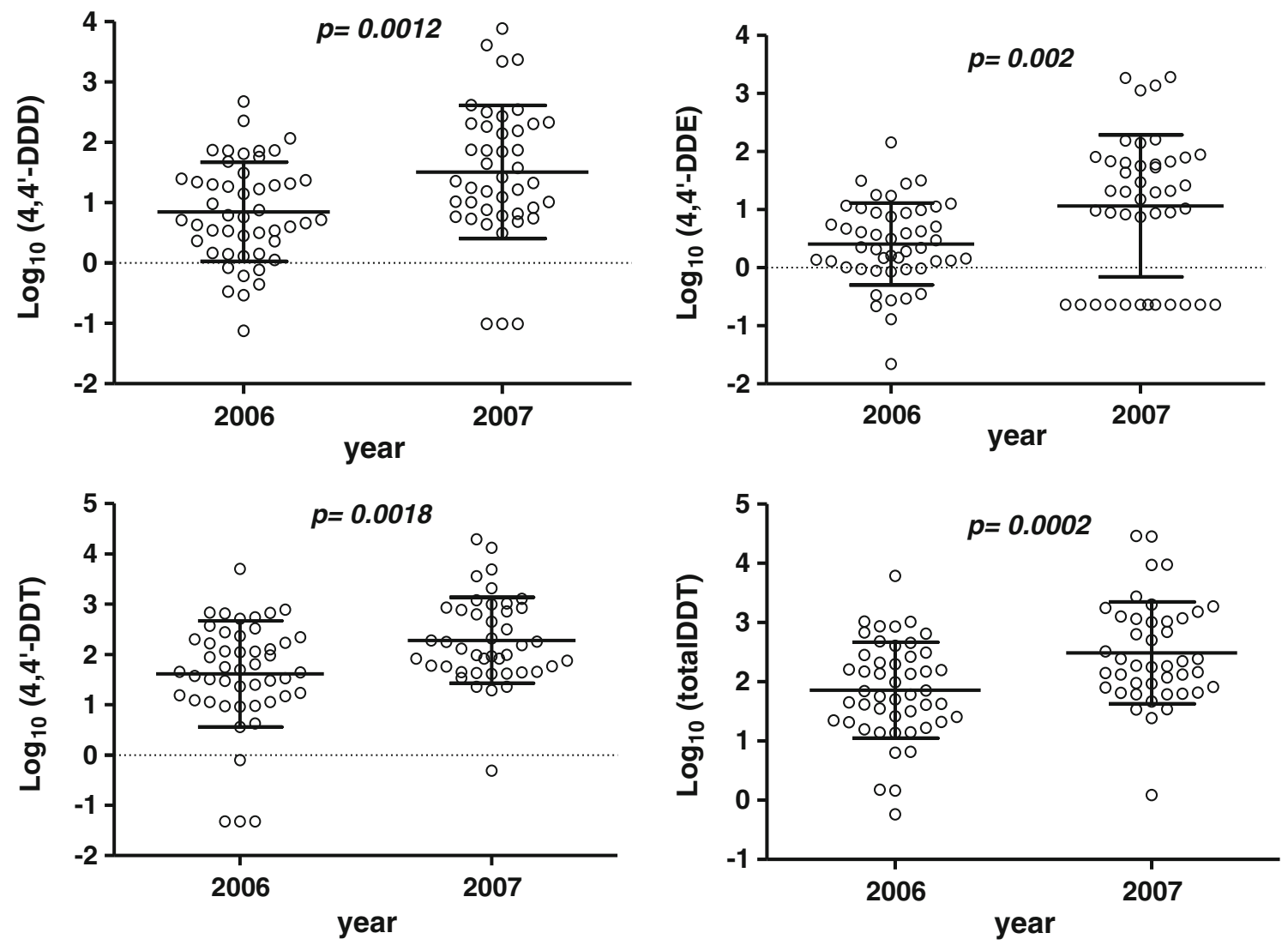

Fig. 1 Comparison of log-transformed DDTs levels (mean and SD nanograms per gram wet weight) in thatch samples from 2006 ( $n=48)$ and 2007 $(n=43)$

was the compound of the highest relative standard deviation, 47-120\%. These higher values may reflect dissimilar 4,4'-DDT transformation after spraying. The observed 4,4'-DDE variability may correspond to the accumulated dispersion resulting from the irregular distribution of the insecticide due to IRS and from compound transformation.

Part of the DDT adsorbed in the thatch evaporates into the dwellings. The concentrations in the wall materials can be used to estimate these levels in the indoor air using the octanol-air constant, $K_{\mathrm{OA}}=C_{\mathrm{O}} / C_{\mathrm{A}}=10^{9.31}$ for $35^{\circ} \mathrm{C}$ (Shen and Wania 2005). This expression can be transformed to reflect the concentrations in air, $C_{\text {air,eq, }}$, from the concentrations in thatch, $C_{\text {thatch }}$, as follows: $C_{\text {air,eq }}=C_{\text {thatch }} /\left(f \times K_{\mathrm{OA}} / d\right)$, which provides an estimate of the equilibrium indoor air concentrations $\left(C_{\text {air,eq }}\right) . f$ is the lipid fraction in thatch $(0.01)$, and $d$ is the octanol density $(0.8 \mathrm{~kg} / \mathrm{L})$. Having in mind kinetic aspects and a partial renewal of the atmosphere in the dwellings, more realistic estimates could be operationally defined as $50 \%$ of $C_{\text {air,eq }}$.

Thus, according to these calculations, the median 4,4'DDT concentrations of 2006 and 2007 (Table 3) correspond to air concentrations of 5.5 and $27 \mathrm{ng} / \mathrm{m}^{3}$, respectively, and the maximum concentrations observed in 2006 and 2007 correspond to 110 and $410 \mathrm{ng} / \mathrm{m}^{3}$, respectively. Studies of indoor 4,4'-DDT spraying with $2 \mathrm{~g} / \mathrm{m}^{2}$ under controlled conditions in rooms from dwellings with plaster covered walls and furnished as per normal household practices have shown gas phase air concentrations in the range of 400$8,600 \mathrm{ng} / \mathrm{m}^{3}$, depending on the time of sampling after spraying (1 h-240 days; Singh et al. 1992). In contrast, remote areas exhibit open air concentrations of 4,4'-DDT in the order of $0.01-0.001 \mathrm{ng} / \mathrm{m}^{3}$ or even less (van Drooge et al. 2002, 2004). A study of DDT contamination due to IRS for malarian control in two districts of South Africa showed indoor air concentrations in the ranges of $750-6,000 \mathrm{ng} / \mathrm{m}^{3}$ (mean $2200 \mathrm{ng} / \mathrm{m}^{3}$ ) and $1.5-28 \mathrm{ng} / \mathrm{m}^{3}\left(\right.$ mean $7.2 \mathrm{ng} / \mathrm{m}^{3}$ ) in treated and untreated dwellings, respectively. The calculated values in Mozambique are consistent with these previously described air concentrations (van Dyk et al. 2010). They suggest that clear DDT exposure through inhalation is a probable mechanism for exposure of their inhabitants. Other exposure routes could be related to dust or particles falling from the treated walls or roofs of the dwellings, e.g., DDT has been found in floor dust (van Dyk et al. 2010). These particles could eventually be inhaled through respiration or ingested if they become mixed with food or water. 


\section{Conclusions}

Measurement of the concentrations of DDT and its metabolites adsorbed onto the thatch and branches of the wall materials provide useful information to estimate the exposure levels of the residents from the dwellings in which this insecticide has been sprayed. Analysis of these wall materials in dwellings from Manhiça has shown higher concentrations of 4,4'-DDT than its metabolites, including 4,4'-DDE, in all cases except two from the 2006 series. Independently of absolute concentrations, the dominance of the former compound evidences that the origin of the former compound is related with the recent use of this insecticide.

Acknowledgments We thank all the families for their participation in the study and the staff of the Manhiça Health Research Center for their support during data and sample collection. We thank E. de Trincheria for her kind support with the chemical analysis of the samples collected in 2006. We also thank Mr. Sergio Gomane (IRS National Focal Point from MISAU) and Eng. Samson Cuamba (National Disposal Project Coordinator from the Mozambican Ministry of Agriculture) for information on DDT use for malaria control. MNM is funded by a Ph.D. Scholarship from Fundació Marfà. CD is supported by the Spanish Ministry of Science and Innovation (MICINN; RYC-2008-02631). The Centro de Investigaçao em Saúde da Manhiça receives core support from the Spanish Agency for International Cooperation and Development (AECID). Funding was received from MICINN (INMA G03/176, Consolider Ingenio GRACCIE, CSD2007-00067), CSIC (PIF06-053), and ArcRisk EU Project (FP7-ENV-2008-1-226534). The CISM receives core support from the AECID.

Open Access This article is distributed under the terms of the Creative Commons Attribution Noncommercial License which permits any noncommercial use, distribution, and reproduction in any medium, provided the original author(s) and source are credited.

\section{References}

AMAP (2008) Centre de Toxicologie du Quebec, Quebec, Canada. http://www.inspq.qc.ca

Barnhoorn IE, Bornman MS, Jansen van Rensburg C, Bouwman H (2009) DDT residues in water, sediment, domestic and indigenous biota from a currently DDT-sprayed area. Chemosphere 77:1236-1241

Battu RS, Singh PP, Joia BS, Karla RL (1989) Contamination of stored food and feed commodities from use of $\mathrm{HCH}$ and DDT in malaria control. Sci Total Environ 78:173-178

Casimiro SLR, Coleman M, Hemingway J, Sharp B (2006) Insecticide resistance in Anopheles arabiensis and Anopheles gambiae from Mozambique. J Med Entomol 43:276-282

Casimiro SLR, Hemingway J, Sharp BL, Coleman M (2007) Monitoring the operational impact of insecticide usage for malaria control on Anopheles funestus from Mozambique. Malaria J 6:142

Garí M, Grimalt JO (2010) Use of proficiency testing materials for the calculation of detection and quantification limits in the analysis of organochlorine compounds in human serum. Anal Bioanal Chem 397:1383-1387
Grimalt JO, Howsam M, Carrizo D, Otero R, Rodrigues de Marchi MR, Vizcaino E (2010) Integrated analysis of halogenated organic pollutants in sub-millilitre volumes of venous and umbilical cord blood sera. Anal Bioanal Chem 396:2265-2272

Marco JAM, Kishimba MA (2005) Concentrations of pesticide residues in grasses and sedges due to point source contamination and the indications for public health risks, Vikuge, Tanzania. Chemosphere 61:1293-1298

MISAU (2006) Ministerio de Saúde de Moçambique. Documento estrategico para o controle da malaria em Mozambique. Programa Nacional de controlo da Malaria

Montgomery CM, Munguambe K, Pool R (2010) Group-based citizenship in the acceptance of indoor residual spraying (IRS) for malaria control in Mozambique. Soc Sci Med 70:1648-1655

Röllin HB, Sandanger TM, Hansen L, Channa K, Odland JØ (2009) Concentration of selected persistent organic pollutants in blood from delivering women in South Africa. Sci Total Environ 408:146-152

Rothman KJ, Greenland S, Lash TL (eds) (2008) Modern epidemiology, 3rd edn. Lippincott William \& Wilkins, Philadelphia

Sereda B, Bouwman H, Kylin H (2009) Comparing water, bovine milk, and indoor residual spraying as possible sources of DDT and pyrethroid residues in breast milk. J Toxicol Environ Health A $72: 842-851$

Shen L, Wania F (2005) Compilation, evaluation, and selection of physical-chemical property data for organochlorine pesticides. J Chem Eng Data 50:742-768

Singh PP, Chawla RP (1988) Comparison of sulphuric acid treatment and column chromatographic clean-up procedures for the gas chromatographic determination of organochlorine compounds in some food commodities. J Chromatogr 457:387-392

Singh PP, Battu RS, Kalra RL (1991) Absorption of DDT and HCH residues by wheat during storage in rural houses treated with these insecticides for malaria control. J Stored Prod Res 27:131-134

Singh PP, Udeaan AS, Battu S (1992) DDT and HCH residues in indoor air arising from their use in malarian control programmes. Sci Total Environ 116:83-92

UNEP (2008) Stockholm convention on persistent organic pollutants (POPs). Global status of DDT and its alternatives for use in vector control to prevent disease. http://www.pops.int/documents/ ddt/Global status of DDT SSC 20Oct08.pdf

van Drooge BL, Grimalt JO, Torres García CJ, Cuevas E (2002) Semivolatile organochlorine compounds in the free troposphere of the Northeastern Atlantic. Environ Sci Technol 36:1155-1161

van Drooge BL, Grimalt JO, Camarero L, Catalan J, Stuchlik E, Torres Garcia CJ (2004) Atmospheric semivolatile organochlorine compounds in European high-mountain areas (Central Pyrenees and High Tatras). Environ Sci Technol 38:3525-3532

Van Dyk JC, Bouwman H, Barnhoorn IE, Bornman MS (2010) DDT contamination from indoor residual spraying for malaria control. Sci Total Environ 408:2745-2752

Waliszewski SM, Carvajal O, Infanzon RM, Trujillo P, Aguirre AA, Maxwell M (2004) Levels of organochlorine pesticides in soils and rye plant tissues in a field study. J Agric Food Chem 52:7045-7050

WHO (2006) Indoor residual spraying. http://malaria.who.int/docs/ IRS-position.pdf

WHO (2007) The use of DDT in malaria vector control. http://www. who.int/ipcs/capacity-building/who_statement.pdf

Yáñez L, Ortiz-Pérez D, Batres LE, Borja-Aburto VH, Díaz-Barriga F (2002) Levels of dichlorodiphenyltrichloroethane and deltamethrin in humans and environmental samples in malarious areas of Mexico. Environ Res 88:174-181 